\title{
Pheromones -Psychosexual Stimulants
}

\author{
Anand Malankar ${ }^{1}$ and Sudhir Sawarkar ${ }^{1 *}$ \\ ${ }^{1}$ QRServes Global LLC, Sharjah Media City, Sharjah, United Arab Emirates.
}

Authors' contributions

This work was carried out in collaboration between both authors. Authors AM and SS equally contributed design, literature review, statistical analysis of the study. Author AM wrote the first draft of the manuscript. Author SS managed the analyses and finalization of the study. Both authors read and approved the final manuscript.

Article Information

DOI: $10.9734 / A R R B / 2021 / v 36 i 430361$

Editor(s):

(1) Dr. Robin Maskey, BPKIHS, University in Dharan, Nepal.

Reviewers:

(1) Hussin Jose Hejase, Al Maaref University, Lebanon.

(2) Hisaya Tanioka, Japan

Complete Peer review History: http://www.sdiarticle4.com/review-history/66983

Review Article

Received 11 February 2021

Accepted 21 April 2021

Published 24 April 2021

\begin{abstract}
In the quest of understanding the phenomenon of sexual attraction and sex appeal between opposite sex, there are various elements that are responsible like Physical attraction, Smell, body Odor, Voice Pitch and Facial Features. The Physical attraction may be the oldest way of understanding sex appeal, however new studies are uncovering various other unexpected factors like smell, voice pitch, and facial expressions as an important aspect of sexual arousal. The role of smell influence on sexual attraction and other behavioral aspect is crucial because humans can smell around 10,000 different aromas knowingly, however there are array of insensible aromas that we are not aware off which we are smelling day in and day out. They are responsible for behavior. The effects of pheromones on psychosexual behavior on human have been studied to great extent however there is limited understanding on exact role of pheromone communication and its mechanism. Pheromones are commonly used in perfumery as fixative. However, the usage of pheromones would mean more effective as real sexual fascination, execution of this tactic will have paradigm shift in perfumery industry which is a great approach to move from monarchy of art to scientific acquaintance. This review is an attempt of compiling the findings from key researches related to use of Pheromones in humans and few animals. We have further discussed the role of pheromones, their molecular aspects and impact on behavioral and physiological aspects. Our study indicates that pheromones are strong psycho-sexual stimulant in animals and humans,
\end{abstract}

\footnotetext{
*Corresponding author: E-mail: sudhir.sawarkar@qrserves.com, spsjaipurnationaluniversity@gmail.com;
} 
commercially many attempts have been made to prove their significance. There is tremendous scope to explore the potential of Pheromones in reenergizing human sexual life which is greatly impacted due to stress, fatigue and age factor.

Keywords: Pheromone; psychosexual stimulants; perfume; aromatherapy; fine fragrances; cosmetics.

\section{INTRODUCTION}

Recently various studies have been carried out by various researchers in regard to human pheromones which prove that these can be sensed by human's main olfactory system. These olfactory signals further convey to sites in hypothalamus that is responsible for regulation of reproduction activities. A plethora of studies and literature reviews show that it is evident that the psychosexual behavior of putative sex human pheromones is perceived by human. This phenomenon can be further enhanced by offering an appropriate blend of human pheromones and perfumery ingredients to the subjects [1].

\section{DEFINITION AND TERMS}

\subsection{Pheromones}

Pheromone is a Greek word which consists of two parts: 'Pherien' means to carry, and' Hormons' means to excite. These Pheromones'are basically chemical molecules which secrete outside of human bodies and are

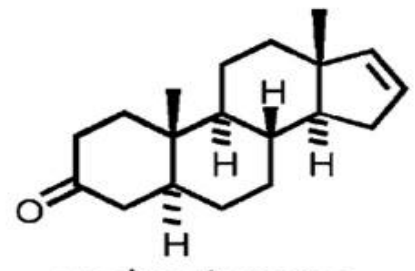

androstenone

(5 $\alpha$-androst-16-en-3-one)

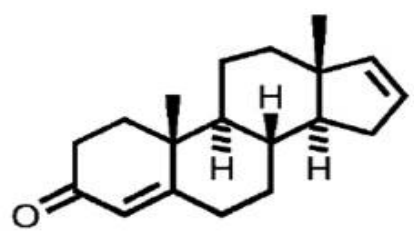

androstadienone (androsta-4,16-dien-3-one) responsible for certain human behavior. The various forms of Pheromone listed are Sex Pheromone, Food Trail Pheromone, and Alarm Pheromones. Apart from the above, there are other Pheromones, which are responsible for a specific behavior and physiological pattern of same class of species [2]. Pheromones induce activity in other individuals, such as sexual arousal, intimate opposite sex and to attract opposite sex. Some chemicals have been investigated for pheromone actions in humans, but evidence is weak, however if we have a proper blend of pheromones with certain selective perfumery compounds then we can increase the effect by many folds [1].

Fig. 1 Depict the chemical structures of key human pheromones. Worth noting that a specific pheromone like and rostadien one, a male sweat component, increases attraction, affects mood, cortisol levels and activates brain areas linked to social cognition. There are studies which state that androstadienone is responsible for enhancement of supportive behavior in males which clearly signifies the effects of Pheromones on Humans behavior [4].

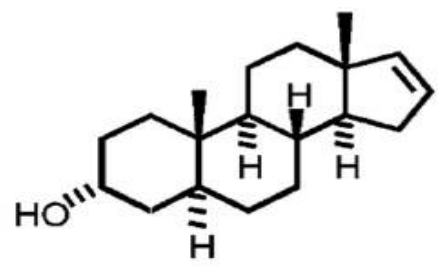

androstenol

(5 $\alpha$-androst-16-en-3 $\alpha$-ol)<smiles>C[C@]12C=CC[C@H]1C1CCc3cc(O)ccc3[C@@H]1CC2</smiles>

estratetraenol

(estra-1,3,5(10), 16-tetraen-3-ol) 
<smiles></smiles>

Formula C19H280 Molecular Mass 272.432 $\mathrm{g} / \mathrm{mol}$

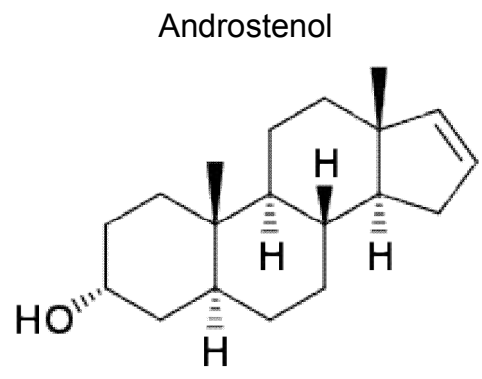

Formula C19H30O Molecular Mass 274.448
$\mathrm{~g} / \mathrm{mol}$

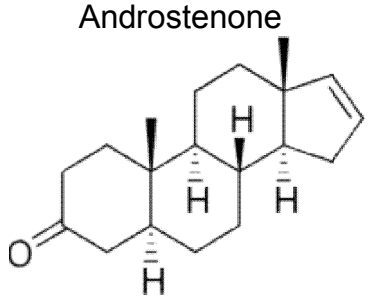

Formula C19H280 Molecular Mass 272.432 $\mathrm{g} / \mathrm{mol}$

Androsterone<smiles>C[C@]12CC[C@H]3[C@@H](CC[C@@H]4C[C@H](O)CC[C@]34C)[C@@H]1CCC2=O</smiles>

Formula C19H30O2 Molecular Mass 290.447 $\mathrm{g} / \mathrm{mol}$

Fig. 1. Structure of key human pheromones [3]

\subsection{The Putative Vomeronasal Organ [VNO] in humans}

VNO is a paired auxiliary olfactory sense organ located in the soft tissues of nasal septum and is located near nasal cavity just above the mouth. The VNO is vital part of human nose system which is surrounded in a cartilaginous capsule and parted apart from olfactory epithelium. The VNO neurons have two different types of receptors which differ from each other from the large family of odorant receptor. The function of VNO receptor is to sense nonvolatile chemical cues which require direct physical contact with the source of odor leading to the activation of olfactory bulb. The sense at VNO predicts the reproductive, defensive and ingestive behavior which are responsible neuroendocrine secretion [5].

\subsection{The Vomeronasal Organ [VNO] and Chemical sensitivity}

The VNO is a bilateral tubular organ located in the nose which commonly serves a functional role in animalsincluding chemical sensitivity and environmental chemicals reactions, whereas in humans, the functional role of VNO towards chemical sensitivity is debatable, however testified characteristics of Human VNO pertaining to chemical sensitivity to airborne chemical exposure and capacity to identify the effects are studied in detail. The demonstration of an active, adult VNO could have substantial influence on environmental toxicology. This signifies that there exists some correlation ship between VNO and chemical sensitivity [7].

The impact of pheromones on consumer buying pattern and repurchase pattern have been extensively studied. To reap commercial benefits, there are various studies that have been patented on Pheromones, however there are limited studies and evidence that have been quoted on the subject, mode of action and its mechanism [8].

\section{REVIEW OF KEY RESEARCH STUDIES IN THIS FIELD}

When we searched NCBI PubMed data base on 8th of Feb 2021 we got the number of studies in the last decade which showed that there is increased interest in the pheromones and its effectiveness. Fig. 3 demonstrates the results graphically. 
It is evident that the number of research on the subject is growing with time, from 2002 till 2014, with slight decrease during the years 2016-2018, and having as the only exception the years 2020 whereby the research is lower due to COVID 19 pandemic situation. However, the trend suggests that research on the subject would be on the rise in the quest of knowledge to know the role of pheromones on human behavior.

The objective here is to understand the larger role of smell influence on sexual attraction and other human behavioral aspects. Humans can smell 10,000 different aromas knowingly, however there are array of insensible aromas that we are not aware off which we are smelling day in day out [8].

While there is huge literature available on this subject, we reviewed the studies which are quite recent and relevant. These studies explain the vital role of pheromones in sexual attraction in opposite sex, sexual arousal, effect on sexual behavior and its consequences on humans.

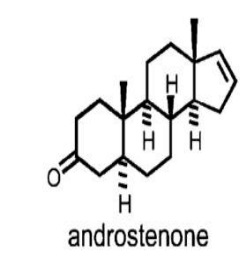

(5 $\alpha$-androst-16-en-3-one)

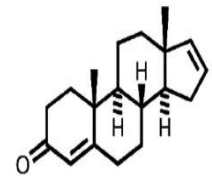

androstadienone (androsta-4,16-dien-3-one) (estra-1,3,5(10),16-tetraen-3-ol)

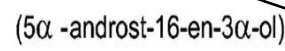

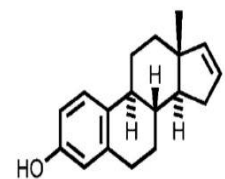

estratetraeno
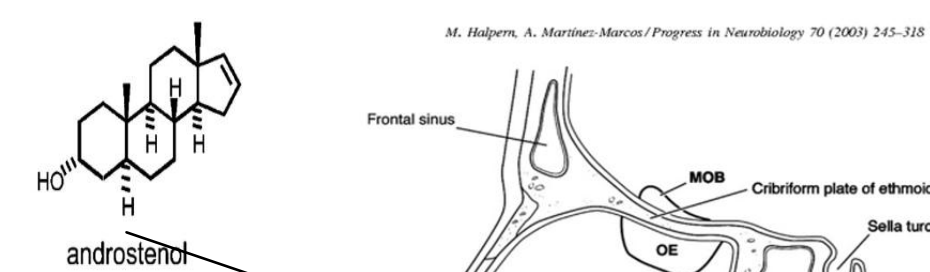

Fig. 2. VNO spot where pheromone molecules are perceived [6]

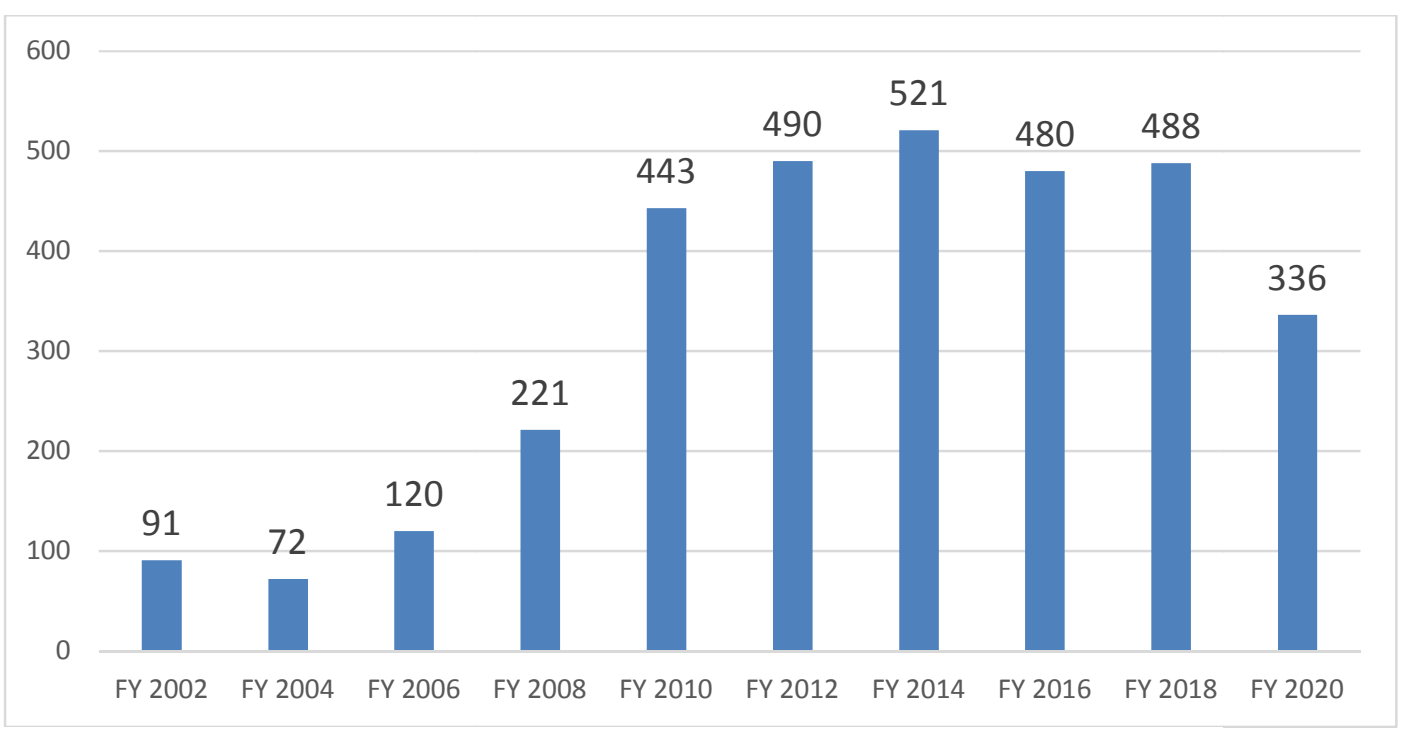

Fig. 3. Number of research studies related to pheromones during last decade 
Bhutta [9] concluded his research stating that odor and smell play an important role in life, from childhood to adult and old age. Right from birth to death, olfactory signals have sequential effects on life which affects behavioral aspects of life including culture, memories, and emotions, which add to life's overall enjoyment and which plays vital role in quality of life which further contributes to human evolution, survival, and enjoyment. About olfactory sense, Bjering [10] have carried out olfactory research and mentioned that, in mammals the Olfactive sense which is responsible for behavior like reproduction, social behavior and feeding is not known to greater extent moreover the role of pheromones in behavior is still a question mark. According to Stowers [11], pheromones could be sensed or perceived in a two-component system viz. signaling pheromones and receiving sensory neurons. Pheromones are bioactive compounds where in only few of them have been known so far and classical essay says that these are nonvolatile vomeronasal sensory neurons which regulate social behavior. According to Frey [12], pheromones are basically aliphatic acids that may or may not have perceivable odor recognized by specific receptor and the stimulation of which induces neuroendocrine reactions that affect individual behavior. In case of humans, almost $70 \%$ of the olfactory receptors have become non-functional but remaining senses can detect emotional reaction connoting a non-verbal signal of social response. Some olfactory cues have been seen with reference to experiments accompanied.

\subsection{Olfactory Cues}

The animal study done by Mornex [13] on genetic, biochemical, and electrophysiological aspects, suggests that pheromones-based deeds together with male sexual activities in mice are channeled via main Olfactive sensing organs. These results depict the provocative hypothesis that pheromones may signal via Main Olfactory Epithelium [MOE]. Whereas in animals, this phenomenon is perceived with the help of major sensory organs called Vomeronasal Organ [VNO] which can identify the pheromones notes which are responsible for their sexual attraction. According to Keverne [14], the Vomeronasal organ is paired with auxiliary olfactory sense organ located in the soft tissues nasal septum and is located near nasal cavity just above the mouth. The VNO is vital part of human nose system which is surrounded in a cartilaginous capsule and parted apart from olfactory epithelium. The VNO neurons have two different types of receptors which differ from each other from the large family of odorant receptor. The function of VNO receptor is to sense nonvolatile chemical cues which require direct physical contact with the source of Odor leading to the activation of olfactory bulb. The sense at VNO predicts the reproductive, defensive and behavior which are responsible for neuroendocrine secretion. Besides this Monti-Bloch [15] further carried out the study on humans Vomeronasal organ which has tendency to evolve with time and exists in all grown-up adults. The VNO has exceptional bipolar microvillar cell which shows physiological properties like the chemosensory receptor cell of the mammalian species. The adult human VNO senses gender specific behavioral changes noticed by nervous system, which shows the sensing capability and functionality of human VNO. Friebely and Rako [16] studied the phenomenon of humans' sociosexual behavior in post-menopausal women which can be enhanced with the help of sex pheromones. The experiment with duration of 6 weeks was conducted with tested chemically produced formula from underarm excretion from sexually active and fertile women participants. A panel of 44 members with average age of 57 years of post-menopause women were studied using a technique of double-blind placebocontrolled strategy to test a pheromone molecule added to their favorite perfume to know if this enhances their romance in their life. During this period, it is observed that the pheromone formula with $40.9 \%$ than placebo $13.6 \%$ demonstrated that participants showed an increase in their own frequency of nuzzling, kissing and affection. This clearly indicates that post-menopausal women have sex attraction effects when the regular perfume formulation is topped with known pheromone molecules. According to Grammer [17], his results proved that the phenomenon of Olfactive signal is quite normal in animals. In humans the olfactory signals have seen substantial scientific attention after the detection of their olfactory system. In the past, less importance had been given to human sense of odor. It is obvious that humans have great sense of Olfactive signals which are responsible for certain behavior besides these facts, humans are also capable to secrete and recognize certain selective pheromones which may play vital role in their social, interactive and reproduction ecology. It is evident that the role of olfactory communication in humans and its sexual behavior is been influenced by pheromones. 
Cherry [18] compiled the animal and human studies evaluating sex variances in the ability of sensing pheromones with the help of main Olfactive system that is responsible for manifestation of Psychosexual behavior in males and females. The sexually dimorphic of human pheromones are facilitated through main olfactory inputs to the amygdala which eventually transfers olfactory information to sites in the hypothalamus that regulates psychosexual behavior pattern and reproduction. A methodical study has been done by Clain [14]on 80 common odorants on men and women and figured out that women are better than men in identifying 74 stimuli. Another study by Doty [19] indicates that women have better sense than Men in picking human body Odor to male \& female classes. T Wyatt [20] says that there exists the phenomenon of attraction in same species due to release of pheromones and this fact is established long back. Wyatt further proposed that the breeding season sexual smell of mammals, goat, crocodile etc. and other species is been evolved through sexual smell of smelliest male through the choice of female. However, this leads to theone million-dollar question: does Human Pheromones exist? Hence, there is a need to study the subject with greater detail and this is chemically explored if the early signs are validated which can lead to identification of Human Pheromones. On a detailed study on humans by Grammer and Jutte [21], it is categorically mentioned that the role of smell, sense and Odor is partially neglected by medical science as far as Human reproduction is concern. The female gets sensitized and attracted towards Male sweat which have direct impact on female menstrual cycle and ovulation. Besides these pheromones secreted by female have direct impact on male and may induce hormonal changes in males. The sex specific reproductive interest has been discussed in detail to understand phenomenal influence on both the sexes which is of significance and of evolutionary limitations

\subsection{Sex Specific Reproductive Interest}

According to Trotier [22], in animals the sense of smell and signal of pheromones are more evident compared to Humans. The Vomeronasal organ of animals is more active compared to humans, however there are certain pheromones which have been perceived by Humans. In a view of Grammer [17] animals' Olfactive signal is very common and an established phenomenon, however in recent years the human Olfactory communication has accrued vast scientific interest. The vital role of sensory smell of humans have been underestimated in the past, it was assumed that the humans' optical senses are more developed with extremely established power of vision but with comparative less developed sense of smell. Certain pheromones play a vital role in the behavior and reproduction biology of Human. The effect of pheromones and its olfactive cues plays crucial role in Human sexual behavior. Cohn [23] contends that Pheromones are the substances secreted by animals which are sensed by other animals of the same species and thereby showing the development of response in certain way which in terms can be translated to sexual attraction. These pheromones can be sensed by olfactory organ or by contacts and those pheromones are found on different parts of the body like, skin, saliva, vaginal secretion, glands. A study by Zaviacic, Sisovsky and Zaviacic [24] depicts that theodor communication in humans is of high importance which is responsible for sexual life as well as relationships like those between mother and child and to identify family members. Specifically, Pheromones have effect on selection of opposite partner during communication between two sexes may be also influenced by pheromone-based perfumes and cosmetic perfumes as far as they select it appropriately. Sergeant [25] categorically mentioned that Olfactive sense is historically the most important form of communication in animals however, Olfactive sense has been given less importance for humans. However, recent research by Hoover KC [8] documented that humans have strong olfactory sensitivity along with ability to send Odor which have potential to influence human physiology and behavior. The process of body Odor production and detection is studied concentrating on possible sex difference in such ability. The ability of females to sense the male body Odor and its physiological and behavior is well thought about.

\subsection{Pheromones Properties on Human Behavior}

A detailed study has been put forward by Pause [26] on the effect of pheromones properties on the mood change and human behavior. The study had been conducted using androstenone exposure to investigate local preferences. It is shown that heterosexual women and homosexual men preferred seats spread with and rosten one. McClintock [27] carried out a detailed study on Human pheromones and 
according to him, chemo sensorial communication may happen in human via the Vomeronasal organ and that of hormonal sense capability. Another researcher called Monti-Bloch [15] categorically mentioned that steroids may act as gender specific and may produce chemical signals in Humans which can be sensed via the Vomeronasal organ which affects hormonal levels.

Winman [28],stated that there is not enough data to prove that pheromones can promote an increase in human socio-sexual behavior. Therefore, it is very crucial to establish the fact using a greater number of panelist.

Olsson [29] carried out a detailed study on Humans to understand the effect of pheromones on men and women. He has figured out that a female pheromone may alter mood in men and that the social context [male or female subjects] may alter how men respond to the exposure to pheromones. A potential female pheromone may alter mood in men and that the social context may alter how men respond to exposure. According to Papaloucas[30], the role of pheromones and testosterones has been studied in sports activity especially for athletes whether pheromones have any effects on their performance. Zaviacic, Sisovsky and Zaviacic [24] reported that Odor communication in men is certainly of significance even though it is unconscious, rather than active as compared to subhuman primates. In addition to sexual life, it also touches various aspects of human life for example mother-child relationship, resemblance with their family members with their peculiar Odor as well as another parameter inspected thus far.

\subsection{Pheromones Effect upon the Choice of Appropriate Partner of the Opposite Sex}

Pheromones may affect the choice of appropriate partner of the opposite sex by the creation of precisely substantial responses during communication between the two sexes. For example, sexual life and its manifestations may be influenced by pheromone-based perfumes or classical cosmetic perfumes, as far as these are designed and used suitably. It is much easier if the partners are of the olfactory type where for both partners the shared olfactory parameters are the most attractive for their sexual life and its parameters, which meaningfully contributes to the quality of their overall way of life and living.
Deng \&Feng [31] studied and established the significant correlation of Olfactive sensitivity and erectile dysfunction in fully-grown males. Damage of Olfactive sensitivity is common in patients with Erectile dysfunction and rhinology disease. In view Peter A. Brennan [32] humans arm pits are prime source of natural pheromones and its smell changes along with puberty age. According to Peter A. Brennan [32] the Human Pheromones study will surprise us for sure. Human conducts and chemical secretions are so multifaceted that the research is challenging, and no pheromones have been conclusively identified. The secretion from arm pits have been studies using modern techniques like Gas liquid chromatography to understand the molecular structure and volatility of the chemical molecules which are responsible for certain behavior in humans like certain pheromones causes menstrual synchrony in females. Cherry\& Baum [33] categorically mentioned that psychosexual behavior of human sex pheromones is perceived by humans through Olfactive route which eventually passes the conveyed Olfactive signal on site, noticed by the human's nose, thus regulating reproduction.

According to Berliner, Jennings-White \& Lavker [34], in the perfumery industry usually mammalian pheromones are used in parts as a fixative to enhance the tenacity of the perfume or used as the carrier to enhance odor experience. However, the pheromonal effects shall be designed in perfumes to enhance sexual attraction instead of being used just as fixatives or carrier. The sensual attractiveness is related to pleasant scent; and the appropriate approach is to use natural human Pheromones which could be more effective as true sensual attraction. Accordingly, Winman[28] Pheromones which are being used exclusively in fragrances to claim an increase of psycho-sexual behavior and attractiveness in humans, need to be studied in detail and shall be substantiated with adequate data. Hence it is clear that more research is required using matched homogeneous group of participants. Furthermore, according to Zaviacic, Sisovsky and Zaviacic [24], the response during communication may also be influenced by welldesigned pheromone-based perfumes if this is being selected properly between the two sexes, first in sexual life and its manifestations this would lead to happier sexual life. Singer [35] concluded, that mammalian pheromones are wildly used as fixatives in perfumery industry to enhance the fragrance substantively and perfume linger, however if we blend a proper 
perfume with a variety of combination of pheromones in appropriate percentage by understanding the fragrance, would lead to a scientific approach to achieve sexual attraction. The usage of human pheromones along with selective perfume ingredients would lead to paradigm shift in perfume industry as perfumery moves from art to scientific approach.

\section{DISCUSSION}

Section two offered a detailed review of the related literature on Human pheromones and its effect on human psychosexual behavior. It is very clear that lot of work has been done to understand the effects of human pheromones however there are many areas that need to be explored. For instance, from the above review the action and mechanism of role of pheromone in animal especially mammals have been identified and established to the extent that there is crystal clarity on pheromones effects on animal behavior. However. in the case of human pheromones and to understand resultant effects, a systematic approach is required. Such methodology is needed to understand the phenomenon to evaluate molecular level performance and its onsite action must be known as the smell is a very important aspect of human behavior. It is also important to explore areas like secretion of pheromones from various parts of the body. There is also a healthy debate going on related to the effects of human pheromones in regards with opposite sex attractions. In fact, few researchers like Leigh Simmons[36], an evolutionary biologist at the University of Western Australia in Crawley, says that their likely exists human pheromones but its action is unidentified. However, on the contrary, Wyatt [12]is convinced that there exists the role of human pheromones on sexual attraction although a thorough study shall be done to reevaluate the role of pheromones in understanding sexual attraction in deeper sense to the molecular level and secretion of pheromones across various parts of the body. A drive to publish more undesirable findings on the subject had compelled Wyatt [12] to concentrate on studies which are more focused on Human pheromones.

\section{CONCLUSION}

Based on the reviewed literature, it can be stated that human pheromones can be sensed by humans' main olfactory system. These olfactory signals further convey to sites in hypothalamus that is responsible for regulation of reproduction activities. The reported literature showed that it is evident that the psychosexual behavior of putative sex human pheromones is perceived by humans and this phenomenon can be further enhanced by selecting the appropriate blend of human pheromones and perfumery ingredients. However, the same reported literature reflects that there is a lack of research in comparative studies, the synergistic effect of pheromones along with certain perfumery ingredients which give a connotation of sexual attraction in opposite sex is not been greatly studied. Hence, there is an apparent need to study the role of synergistic effect of Pheromones and selective perfumery ingredients in understanding the phenomenon of enhancing mood and sexuality using combination of pheromones and selective perfumery ingredients which could be blended in fragrances or similar applications to the benefits of the consumer.

\section{FUTURE RESEARCH POSSIBILITIES}

There is a scope to study the human pheromones to greater extent and understanding the subject down to the molecular level and its effects on human psychosexual behavior.

A study can be planned on sex pheromone molecules which are perceived by humans. In fact, the adult male has ability to sense certain pheromone molecules and females have ability to sense certain specific pheromone molecules which could be responsible for psychosexual behavior in humans. The study eventually will become a tool to communicate their sexual desire and preferences. The Odor is very important aspect of human behavior hence it becomes a necessity to identify the molecules which are responsible for such behavior in opposite sex. Consequently, a study on the synergistic effect of pheromones along with certain perfumery ingredients is needed to compare comprehensively which would give connotation of sexual attraction in opposite sex. The phenomenon will be studied to understand and design unique product proposition in fragrances and personal care market to enhance the efficacy of product by studying synergistic effect of pheromones and perfumery compound.

Further, to improve pheromone delivery to consumer, the development of suitable dosage form can also be explored. Study of most convenient product format which can deliver the 
intended use in efficiently and conveniently can also be planned.

The studies will enable the society with novel pheromone perfume compound for improving sex attraction and behavior which would benefit the end consumer in true sense

\section{DISCLAIMER}

There is absolutely no conflict of interest between the authors and producers of the products mentioned in the research. Also, the research was not funded by the product marketing or manufacturing companies.

\section{ACKNOWLEDGEMENT}

Authors would like to thank Ms. Sulakshana Sawarkar, Managing Director, QRServes Global LLC, UAE for providing resources and support for this study

\section{COMPETING INTERESTS}

Authors have declared that no competing interests exist.

\section{REFERENCES}

1. Cherry JA, Baum MJ. Sex differences in main olfactory system pathways involved in psychosexual function. Genes Brain Behav. 2020;19(2):e12618.

DOI: $10.1111 / \mathrm{gbb} .12618$.

EPUB 2019 Nov 4.

PMID: 31634411

2. Wisman A, Shrira I. Sexual Chemosignals: Evidence that men process olfactory signals of women's sexual arousal. Arch Sex Behav. 2020;49(5):1505-1516.

DOI: $10.1007 / \mathrm{s} 10508-019-01588-8$

EPUB 2020 Feb 5.

PMID: 32026223;

PMCID: PMC7299914

3. Evgueny V. Aronov, Edward P. Zinkevich, Molecular design of substances with the androstenone odor. 2,4'-substituted 4cyclohexylcyclohexanones-a new class of androstenone-like odorants. Chemical Senses. 1993;18(3):229-243.

Available:

https://doi.org/10.1093/chemse/18.3.229

4. Marazziti D, Torri P, Baroni S, Catena Dell'Osso M, Consoli G, Boncinelli V. Is androstadienone a putative human pheromone? Curr Med Chem. 2011;18(8):1213-9.

DOI: $10.2174 / 092986711795029654$

PMID: 21291365.

5. Trotier D. Vomeronasal organ and human pheromones. Eur Ann Otorhinolaryngol Head Neck Dis. 2011 Sep;128(4):184-90. DOI: 10.1016/j.anorl.2010.11.008. EPUB 2011 Mar 5. PMID: 21377439.

6. Halpern M, Martínez-Marcos A. Structure, and function of the vomeronasal system: An update. Prog Neurobiol. 2003;70(3):245-318.

DOI: $10.1016 / \mathrm{s} 0301-0082(03) 00103-5$

PMID: 12951145.

7. Kouros-Mehr H, Pintchovski S, Melnyk J, Chen YJ, Friedman C, Trask B, Shizuya $\mathrm{H}$. Identification of non-functional human VNO receptor genes provides evidence for vestigiality of the human VNO. Chem Senses. 2001;26(9):1167-74.

DOI: $10.1093 /$ chemse/26.9.1167

PMID: 11705802.

8. Hoover KC. Smell with inspiration: The evolutionary significance of olfaction. Am J Phys Anthropol. 2010;143Suppl51:63-74.

DOI: 10.1002/ajpa.21441

PMID: 21086527.

9. Bhutta $M$, Carling $P$, Clark M. Editorial. J Laryngol Otol. 2019;133(1):1-2.

DOI: $10.1017 / S 0022215118002293$

PMID: 30744729.

10. Bjering S, Deinboll II, Maehlen J. Luktesansen [The olfactory sense]. Tidsskr Nor Laegeforen. 2000;120(30):3719-25. Norwegian. PMID: 11215945.

11. Stowers L, Marton TF. What is a pheromone? Mammalian pheromones reconsidered. Neuron. 2005;46(5):699702.

DOI: 10.1016/j.neuron.2005.04.032. PMID: 15924856.

12. Frey J. Les phéromones: An moyen de communication sous-estimé dans l'espècehumaine [Pheromones: an underestimated communication signal in humans]. Ann Biol Clin (Paris). 2003;61(3):275-8. French.

PMID: 12805004.

13. Mornex R. Pherormones [Pherormones]. Lyon Med. 1974;232(13):49-55. French. PMID: 4217406.

14. Keverne EB. The vomeronasal organ. Science. 1999 Oct 22;286(5440):716-20. DOI: $10.1126 /$ science.286.5440.716 
PMID: 10531049.

15. Monti-Bloch $L$, Jennings-White $C$, Berliner DL. The human vomeronasal system. A review. Ann N Y Acad Sci. 1998;855:37389.

DOI: $10.1111 / \mathrm{j} .1749-6632.1998 . t b 10595 . x$ PMID: 9929629.

16. Friebely J, Rako S. Pheromonal influences on sociosexual behavior in postmenopausal women. J Sex Res. 2004;41(4):372-80.

DOI: $10.1080 / 00224490409552244$

PMID: 15765277.

17. Grammer K, Fink B, Neave N. Human pheromones and sexual attraction. Eur $\mathrm{J}$ ObstetGynecolReprod

Biol. 2005;118(2):135-42.

DOI: 10.1016/j.ejogrb.2004.08.010

PMID: 15653193.

18. Cherry JA, Baum MJ. Sex differences in main olfactory system pathways involved in psychosexual function. Genes Brain Behav. 2020;19(2):e12618.

DOI: $10.1111 / \mathrm{gbb} .12618$

EPUB 2019 Nov 4.

PMID: 31634411.

19. Doty RL. Olfaction. Annu Rev Psychol. 2001;52:423-52.

DOI: 10.1146/annurev.psych.52.1.423

PMID: 11148312.

20. 20 Wyatt TD. Pheromones. Curr Biol. 2017;27(15):R739-R743.

DOI: 10.1016/j.cub.2017.06.039.

PMID: 28787598.

21. Grammer K, Jütte A. Der Krieg der Düfte: Bedeutung der Pheromone für die menschlicheReproduktion [Battle of odors: significance of pheromones for human reproduction]. Gynakol Geburtshilfliche Rundsch. 1997;37(3):150-3. German.

DOI: $10.1159 / 000272845$

PMID: 9483874.

22. Trotier D. Vomeronasal organ and human pheromones. Eur Ann Otorhinolaryngol Head Neck Dis. 2011;128(4):184-90.

DOI: 10.1016/j.anorl.2010.11.008

EPUB 2011 Mar 5.

PMID: 21377439.

23. Cohn BA. In search of human skin pheromones. Arch Dermatol. 1994;130(8):1048-51.

PMID: 8053704.

24. Zaviacic $M$, Sisovsky $V$, Zaviacic $T$. Cosmetic perfumes vs. human pheromones (natural chemical scents) of the human female and male in signalling and performing context of their sexual behaviour. Bratisl Lek Listy. 2009;110(8):472-5.

PMID: 19750984.

25. Sergeant MJ. Female perception of male body odor. Vitam Horm. 2010;83:25-45.

DOI: 10.1016/S0083-6729(10)83002-X.

PMID: 20831941.

26. Pause BM. Are androgen steroids acting as pheromones in humans? Physiol Behav. 2004;83(1):21-9.

DOI: 10.1016/j.physbeh.2004.07.019 PMID: 15501487.

27. McClintock MK. On the nature of mammalian and human pheromones. Ann N Y Acad Sci. 1998;855:390-2.

DOI: 10.1111/j.1749-6632.1998.tb10596.x PMID: 9929630.

28. Winman A. Do perfume additives termed human pheromones warrant being termed pheromones? PhysiolBehav. 2004;82(4):697-701.

DOI: 10.1016/j.physbeh.2004.06.006 PMID: 15327919.

29. Lundström JN, Olsson MJ. Subthreshold amounts of social odorant affect mood, but not behavior, in heterosexual women when tested by a male, but not a female, experimenter. Biol Psychol. 2005;70(3):197-204.

DOI: 10.1016/j.biopsycho.2005.01.008

Epub 2005 Mar 24.

PMID: 16242537.

30. Papaloucas M, Kyriazi K, Kouloulias V. Pheromones: a new ergogenic aid in sport?. Int J Sports Physiol Perform. 2015;10(7):939-40.

DOI: 10.1123/ijspp.2014-0226.

Epub 2015 Feb 24.

PMID: 25710097.

31. Zhang $Y N$, Zhu XY, Fang LP, He $P$, Wang ZQ, Chen G, Sun L, Ye ZF, Deng DG,

$\mathrm{Li}$ JB. Identification and Expression Profiles of Sex Pheromone Biosynthesis and Transport Related Genes in Spodoptera litura. PLoS One. 2015;10(10):e0140019.

DOI: 10.1371/journal.pone.0140019

PMID: 26445454;

PMCID: PMC4596838.

32. Brennan PA. Pheromones and Mammalian Behavior. In: Menini A, editor. The Neurobiology of Olfaction. Boca Raton (FL): CRC Press/Taylor \& Francis; 2010. Chapter 6.

PMID: 21882427.

33. Cherry JA, Baum MJ. Sex differences in main olfactory system pathways involved 
in psychosexual function. Genes Brain Behav. 2020;19(2):e12618.

DOI: 10.1111/gbb.12618. Epub 2019 Nov 4.

PMID: 31634411.

34. Berliner DL, Jennings-White C, Lavker RM. The human skin: fragrances and pheromones. J Steroid Biochem Mol Biol. 1991;39(4B):671-9.

DOI: $10.1016 / 0960-0760(91) 90266-8$ PMID: 1892796.
35. Singer AG. A chemistry of mammalian pheromones. J Steroid Biochem Mol Biol. 1991 Oct;39(4B):627-32.

DOI: 10.1016/0960-0760(91)90261-3

PMID: 1892792

36. Hare RM, Schlatter S, Rhodes G, Simmons LW. Putative sex-specific human pheromones do not affect gender perception, attractiveness ratings or unfaithfulness judgements of opposite sex faces. R Soc Open Sci. 2017;4(3):160831.

(C) 2021 Malankar and Sawarkar; This is an Open Access article distributed under the terms of the Creative Commons Attribution License (http://creativecommons.org/licenses/by/4.0), which permits unrestricted use, distribution, and reproduction in any medium, provided the original work is properly cited.

Peer-review history:

The peer review history for this paper can be accessed here: http://www.sdiarticle4.com/review-history/66983 